Convergence in international business ethics? A comparative study of ethical philosophies, thinking style, and ethical decision-making between US and Korean managers

Article

Accepted Version

Paik, Y., Lee, J. M. and Pak, Y. S. (2019) Convergence in international business ethics? A comparative study of ethical philosophies, thinking style, and ethical decision-making between US and Korean managers. Journal of Business Ethics, 156 (3). pp. 839-855. ISSN 1573-0697 doi: https://doi.org/10.1007/s10551-017-3629-9 Available at https://centaur.reading.ac.uk/72172/

It is advisable to refer to the publisher's version if you intend to cite from the work. See Guidance on citing.

To link to this article DOI: http://dx.doi.org/10.1007/s10551-017-3629-9

Publisher: Springer

All outputs in CentAUR are protected by Intellectual Property Rights law, including copyright law. Copyright and IPR is retained by the creators or other copyright holders. Terms and conditions for use of this material are defined in the End User Agreement. 


\section{www.reading.ac.uk/centaur}

\section{CentAUR}

Central Archive at the University of Reading

Reading's research outputs online 


\title{
Convergence in International Business Ethics? A Comparative Study of Ethical Philosophies, Thinking Style, and Ethical Decision-Making between US and Korean Managers
}

\begin{abstract}
This study investigates the relationship among ethical philosophy, thinking style, and managerial ethical decision-making. Based on the premise that business ethics is a function of culture and time, we attempt to explore two important questions as to whether the national differences in managerial ethical philosophies remain over time, and whether the relationship between thinking style and ethical decision-making is consistent across different national contexts. We conducted a survey on Korean managers' ethical decision-making and thinking style, and made a crosscultural, cross-temporal comparison with the results presented by previous studies that surveyed Korean and US managers with the same questionnaire at different points in time. Our analysis revealed that Korean managers have become more reliant on rule utilitarianism for ethical decision-making over the last two decades, which is dominantly used by US managers, corroborating our convergence hypothesis built on social contracts theory. However, as opposed to previous research, we found that managers with a balanced linear and nonlinear thinking style do not necessarily make more ethical decisions compared to those with a predominantly linear or nonlinear thinking style. This study contributes to international business ethics literature by presenting a theoretical framework that may explain the convergence of ethical philosophies employed by managers in different national contexts over time, and that the relationship between thinking style and managerial ethical decision-making may not be universal, but contingent on contextual factors.
\end{abstract}

KEY WORDS: social contracts theory, ethical philosophies, thinking style, managerial ethical decision-making, Korea, US 


\section{INTRODUCTION}

Business ethics is neither universal nor static. It is closely associated with two parameters: time and culture (Svensson and Wood, 2003). Ethical values and principles change over time. What was accepted as ethical yesterday may not be regarded as ethical today, and what is perceived to be ethical today may not be perceived to be ethical tomorrow. Business ethics also varies considerably across cultures. Each culture has its own mores of what constitutes ethical and unethical behaviors. Therefore, business ethics involves what is perceived as ethical or not at a specific time in a specific cultural setting. It is noteworthy that cultural contexts also evolve as time goes on. Thus, culture and time are also related although their relationship is unilateral as "time influences culture but culture does not influence time" (Svensson and Wood, 2003, p. 351).

Over the last two decades, the globalization of business has been phenomenal, and its impact has been extensively studied in various fields of international business research including business ethics. The literature on the influence of globalization has often focused on the convergence and divergence debate (Gupta and Wang, 2004; Paik, Chow, and Vance, 2011; Webber, 1969). Many scholars suggested that globalization accelerates the convergence of economic, political, cultural and social aspects around the world, leading to the erosion of national differences (e.g., Levitt, 1983; Seita, 1997). Proponents of the convergence perspective argue that globalization promotes common values, norms and attitudes of business managers across nations as industrialization forced individuals, irrespective of cultures, to adopt industrial attitudes and behaviors such as rationalism and secularism in order to survive in modern industrialized societies (Kelley, Whatley, and Worthley, 1987; Radice, 2000). On the contrary, a number of scholars have pointed out that differences among countries, cultures and societies have not been greatly attenuated with globalization (Ghemawat, 2001, 2007). In particular, the 
divergence advocates contend that national culture is the dominant force in shaping the values, beliefs and attitudes of managers, which leads them to remain different from those in other countries despite the impact of globalization (Ricks, Toyne, and Martinez, 1990).

It is relatively unknown whether the globalization of business entails convergence or divergence in managers' ethical decision-making (Bailey and Spicer, 2007; DeGeorge, 1993). In particular, given that business ethics is a function of both time and culture (Svensson and Wood, 2003), whether the national differences in managerial ethical decision-making still remain or become smaller over time constitutes an intriguing inquiry into international business ethics. Our first research objective is to examine this critical, yet under-explored, inquiry by conducting a cross-cultural as well as cross-temporal comparison of ethical decision-making between South Korean (hereafter Korean) and US managers. Specifically, we build on social contracts theory to develop our theoretical framework that captures the evolution of ethical philosophies underlying managerial ethical decision-making. Social contracts theory advanced by Donaldson and Dunfee $(1994,1999)$ provides a critical insight into the similarities and differences in business ethics among national contexts, which further allows us to examine the convergence and divergence in international business ethics (Bailey and Spicer, 2007; Fritzsche et al., 1995). We predict a convergence of ethical philosophies used by Korean managers into those employed by US managers over the last two decades. We test our hypothesis by comparing the survey results of Korean and US managers' ethical decision-making provided by Fritzsche and Becker (1984) and Fritzsche et al. (1995), which represents the managerial ethical decision-making in the US in the 1980s and Korea in the 1990s, respectively, with the recent survey results provided by Groves, Vance, and Paik (2008) that examines the ethical decision-making of US managers in the 2000s and our own survey results that shows the ethical decision-making of Korean managers in the 
2010s. All four studies utilized the same series of vignettes developed by Fritzsche and Becker (1984) to collect the data. Therefore, they provide an appropriate research setting to compare the managerial ethical decision-making of US and Korean managers at two different points of time on a relatively consistent basis (Choi and Nakano, 2008; Fritzsche et al., 1995; Premeaux, 2004).

Another important, but underdeveloped, aspect of international business ethics concerns the relationship between the thinking style of managers and their managerial ethical decisionmaking. Literature has revealed that managers with different thinking styles, or cognitive style, perceive ethical situations or dilemmas very differently (Fleming, 1985; McIntyre and Capen, 1993; Pennino, 2002). For instance, what seems to be a matter of ethics for some people with a certain thinking style may have no ethical implications for other people with a different thinking style (McIntyre and Capen, 1993). Much of the empirical literature has demonstrated the varying influence of linear (i.e., sensing/thinking) and nonlinear (i.e., intuition/feeling) elements in thinking style on the ethical decision-making, typically utilizing the Myers-Briggs Type Indicator (MBTI) (e.g., McIntyre and Capen, 1993; McIntyre, Capen, and Minton, 1995; White and Manolis, 1997). More recently, based on the data collected from 200 US managers, Groves et al. (2008) demonstrated that managers utilizing a balanced linear/nonlinear thinking style tend to make more ethical decisions compared to managers with a predominantly linear or nonlinear thinking style. Although this finding substantially enhances our understanding of the cognitive basis of managerial ethics, thinking styles also vary considerably across international contexts, and so does the link between thinking style and decision-making across countries (Allinson and Hayes, 2000; Nisbett et al., 2001). Indeed, the literature has recognized significant cultural differences in thinking style and cognitive process, particularly between the East and the West (Abramson, Keating, and Lane, 1996; Kume, 1985; Redding, 1980). Accordingly, we believe it is 
worth corroborating the findings of Groves et al. (2008) in different national contexts other than the US.

Our second research objective is to test the relationship between thinking style and ethical decision-making found by Groves et al. (2008) in a Korean context. Such an examination may provide a deeper insight into the cognitive basis of business ethics that survives the test of contexts. The extant literature on the national differences in thinking style has often argued that Westerners such as US managers tend to have linear thinking style, usually employing a direct, confrontation-centered strategy using rational criteria for decision-making. On the contrary, East Asians such as Korean managers are prone to utilize nonlinear ways of thinking to make decisions, typically adopting an indirect, agreement-centered, holistic approach based on intuition (Hall and Hall, 1987; Koller and Koller, 2007; Kume, 1985; Paik and Tung, 1999). Accordingly, the Korean context, which is very different from the US, provides an appropriate setting to reexamine the findings of Groves et al. (2008) that managers with a balanced linear/nonlinear thinking style tend to make more ethical decisions.

In the following sections, we first discuss the ethical philosophies underlying the managerial ethical decision-making of both Korean and US managers based on the findings from previous literature. We then review social contracts theory that provides a leading framework for our convergence hypothesis. Next, we discuss the link between thinking style and ethical decisionmaking, and describe our methodology. Finally, the paper concludes with a discussion of our findings, their implications, and limitations.

\section{THEORETICAL FOUNDATION AND HYPOTHESIS DEVELOPMENT}

\section{Ethical Philosophies and Ethical Decision-making of Korean and US Managers}




\section{Ethics position theory}

The ethical decision-making model developed by Rest (1986) involves four basic components: ethical awareness, judgment, intent, and behavior. The model explains that when making ethical decisions, individuals first recognize a moral issue and make a moral judgment, and then establish moral intent and engage in moral behaviors or actions. A number of other factors such as personal characteristics, ethical philosophies, thinking styles, environmental elements and situational factors may also be encompassed in this four-stage ethical decisionmaking process and affect, either directly or indirectly, the individual's ethical decision or behaviors (e.g., Forsyth, 1980, 1992; Fritzsche and Becker, 1984; Groves et al., 2008; Jones, 1991).

An influential factor in the ethical decision-making process is the individual's ethical or moral philosophies (Forsyth, 1980; Fritzsche and Becker, 1984). Forsyth (1980) contends that individuals' personal moral philosophies influence their ethical judgments and actions in morally toned situations. Individuals base their ethical decision-making on a personal 'ethics position' that they have developed over a lifetime of experience in confronting and resolving moral issues (Forsyth, O’boyle, and McDaniel, 2008; Kohlberg, 1976). The ethical position theory highlights two nomothetic regularities: the consequences of the action (teleological models) and the principles (deontological models). The theory identifies the consequences dimension as 'idealism' that mainly focuses on the impact of the action on people's welfare. Highly idealistic people believe that benign outcomes can always be achieved with the right action, while less idealistic individuals pragmatically admit that the undesirable consequences are sometimes unavoidable and often occur along with desired ones. The principle dimension of the theory is 'relativism' which pertains to individuals' emphasis on moral principles as a guide for making 
ethical judgments. Highly relativistic people tend to base their moral judgments on situational events and evaluate the actions taken against specific circumstances, while less relativistic individuals have more cognitive faith in moral principles or universal moral rules and use them when making ethical judgments (Forsyth, 1980, 1992; Forsyth et al., 2008).

Ethical position theory presents that people have varying degrees of idealism and relativism that determine their moral philosophies. The theory identified the four distinct moral philosophies or ethical positions: (i) situationism (high idealism / high relativism), (ii) subjectivism (low idealism / high relativism), (iii) absolutism (high idealism / low relativism), and (iv) exceptionalism (low idealism / low relativism), each of which contains a peculiar moral stance (see Forsyth $(1980,1992)$ for a review).

Scholars have examined these two dimensions of ethics worldwide, demonstrating the cultural variations in ethical positions. The empirical literature has reported that the degrees of idealism and relativism, and their relationship to ethical behaviors vary considerably across national cultures. Forsyth et al. (2008) recently conducted an objective review of the empirical literature on ethical positions across different nations and drew general conclusions about crosscultural differences in the ethical positions. A meta-analysis of 139 independent samples from 81 studies conducted with 30,230 residents of 29 nations (Forsyth et al., 2008) has concluded that Eastern, Western, and Middle Eastern cultures have different moral philosophies that influence individuals' judgments, actions, and emotions in ethically intense situations. The general finding is that exceptionist ethics is more common and strong in Western countries while subjectivism or situationism are more dominant in Eastern countries. Middle Eastern countries tend to show strong absolutism or situationism.

The meta-analysis result revealed that US respondents typically fall into the exceptionist 
category that has relatively low levels of both idealism and relativism, while Korean respondents are most closely associated with situationists who have relatively high levels of both idealism and relativism (Forsyth et al., 2008). Exceptionists are 'deontologists' in that they prefer to rely on moral principles as guidelines for behaviors (low relativism). At the same time, they are also 'utilitarian' in that they pragmatically balance the positive consequences of an action against the negative consequences of an action (low idealism). Their outlook corresponds to a moral philosophy based on 'rule-utilitarianism,' which holds that moral principle is useful as they provide a framework for making choices and for acting in ways that will generally produce the best consequences for all affected parties. On the contrary, situationists usually eschew universal moral principles (high relativism) but still insist that one should produce desirable consequences that benefit all involved (high idealism). Therefore, they tend to prescribe the inspection of situations to reach a contextually appropriate moral evaluation. Situationism corresponds to such skeptical philosophies as 'situation ethics' which argues that an action, to be moral, should be appropriate given the particular context (Fletcher, 1966) and 'value pluralism' which suggests that the consequences of an action determine its moral value (James, 1891). Thus, situationists are closely associated with 'act utilitarianism' which maintains that one must act in ways that will benefit the greatest number of people (Forsyth, 1992; Forsyth et al., 2008).

\section{Linking ethical philosophies to management behaviors}

Fritzsche and Becker (1984) also highlighted that understanding the ethical philosophy held by managers is essential to fathom their ethical behaviors. They made an initial attempt to examine the link between ethical philosophy and managerial ethical behaviors by developing a series of vignettes, each of which describes a decision containing a potential ethical dilemma. 
They argued that the use of vignettes permits one to inject a greater amount of background information and detail into an ethically questionable issue, and thereby, elicit a higher quality of data from respondents in ethical research than is possible from simple questions (Alexander and Becker, 1978; Fritzsche and Becker, 1984). They identified five categories of ethical problems: (i) coercion and control, (ii) conflict of interest, (iii) physical environment, (iv) paternalism, and (v) personal integrity. A 'coercion and control' issue exists when some external force compels a manager to make a specific decision by using threats, extortion, or other sources of power. A 'conflict of interest' situation arises when a manager has multiple interests that are not mutually compatible and may cause harm, if mutually pursued, to individuals or to the firm (Beauchamp and Bowie, 1979). The 'physical environment' is a particular case of conflict of interest in which one of the affected parties is the environment. A 'paternalism' issue concerns the balancing of respect for individual autonomy with a commitment to public welfare. Finally, 'personal integrity' issues occur when decisions raise issues of conscience.

Fritzsche and Becker (1984) utilized three core ethical theories to explain the possible responses to each dilemma: (i) theories of rights that emphasize individual indisputable entitlements, (ii) justice theories that consider the distributional effects of actions, behaviors, or policies, and (iii) act or rule utilitarian theories, which propose that individuals evaluate behavior in terms of its social impact (Cavanagh, Moberg, and Velasquez, 1981). Rights theories focus on the rights and basic legal claims of all individuals, including free consent, freedom of conscience, free speech, privacy, and due process. The theories of justice emphasize decisions based upon fairness, equity, and impartiality, with a particular emphasis on the validity of differential 'merit-based' treatment for individuals according to their contribution to the attainment of organizational goals (Rawls, 1971). Finally, utilitarian theories purport that 
individuals assess behavior in terms of its social consequences. There are two types of utilitarianism. Act utilitarianism proposes that individuals base decisions solely on their outcomes by selecting the act that provides the greatest social good. Rule utilitarianism argues that individuals' action is judged ethical or not depending on whether they followed certain rules under which the action falls (Barry, 1979).

The five vignettes of Fritzsche and Becker (1984) reflect critical ethical issues that deeply concern managers worldwide, irrespective of their national contexts, and hence, subsequently were used in numerous empirical studies across different national contexts (e.g., Becker and Fritzsche, 1987; Fritzsche et al., 1995; Premeaux, 2004; Premeaux and Mondy, 1993; Whitcomb, Erdener, and $\mathrm{Li}, 1998)$. The common finding, regardless of the national contexts, is that managers tend to make their decision about ethical dilemmas in the workplace based on utilitarianism, either act or rule, whereas act utilitarianism generally leads to unethical decisionmaking. Individuals following rule utilitarianism tend to place greater emphasis on ethical interests rather than economic gains, while those adhering to act utilitarianism are more likely to take the opposite position. As act utilitarianism suggests that each individual action is judged exclusively based on its outcome, it could justify a firm's unethical behaviors such as an exploitation of child labor on the ground that such a practice increases its profits and maximizes shareholders' interest. Meanwhile, rule utilitarianism may resolve such a moral loophole as it focuses on the utility of a rule for action.

\section{Ethical philosophies of Korean and US managers in 1980 90s}

The original work of Fritzsche and Becker (1984) presented the survey results of 124 US managers who linked their ethical decisions to the five ethical dilemmas described in the 
vignettes (Table 1). The results showed that utilitarianism predominantly represented the ethical philosophy underlying the US managers' ethical decisions across all five ethical dilemmas except for the 'personal integrity' problem. Few respondents indicated rights or justice theory as their rationale for ethical decisions. The utilitarian responses were divided into rule and act utilitarian philosophies, but their proportion varied across vignettes. US managers tend to rely more on rule utilitarianism for the ethical dilemmas concerning the 'coercion and control' issue and 'paternalism' problem, while they rely more on act utilitarianism for the 'physical environment' dilemma. US managers seem to utilize both rule and act utilitarianism for ethical decisionmaking related to the 'conflict of interest' issue.

In the subsequent research, Fritzsche et al. (1995) conducted a comparative study of the US and three East Asian countries (i.e., Korea, Japan, and Taiwan) utilizing the same series of vignettes. The results of 83 Korean managers revealed that, like US managers, Korean managers predominantly rely on utilitarian philosophies when making ethical decisions (Table 3). However, Korean managers tend to strongly adopt act utilitarianism rather than rule utilitarianism across all ethical problems, except for the 'paternalism' issue which is closely related to the historical trauma of Korean people - Korean (and Japanese) managers would be highly sensitive to the threat of atomic bombs after watching what happened to the Japan in 1945 (Fritzsche et al., 1995).

Fritzsche et al.'s (1995) comparative study concluded that the likelihood of, and justification for, taking an ethically ambiguous behavior varies across ethical issues, and that the cultural impact also varies across different ethical problems (Becker and Fritzsche, 1987; Fritzsche and Becker, 1984). 


\section{Social contracts theory}

Culture plays a pivotal role in the ethical reasoning and ethical attitudes of a person (Christie et al., 2003) because "contrasting cultures of different societies produce different expectations and become expressed in the dissimilar ethical standards of those societies" (Bartels, 1967, p. 23). However, empirical results from various cross-cultural studies have been inconsistent. Some studies have found that significant differences exist in business ethical attitudes and conduct across countries (e.g., Alderson and Kakabadse, 1994; Becker and Fritzsche, 1987; Dubinsky et al., 1991; Honeycutt, Siguaw, and Hunt, 1995), while others have reported little differences across national cultures in the ethical standards of business practices (Lee, 1981), perceived ethical problems (Armstrong et al., 1990), and moral attitudes in business (Preble and Reichel, 1988).

A social contracts theory of business ethics developed by Donaldson and Dunfee (1994) laid an important foundation to unravel seemingly contradictory effects of national cultures on business ethics. While recognizing that national cultures often matter in individuals' ethical decision-making, social contracts theory raised the question of when and how they matter (Bailey and Spicer, 2007). The theory contends that social definitions of ethical behaviors may come from two different types of ethical norms, namely, 'hypernorms' and 'community norms.' Hypernorms refers to the fundamental principles of human existence that operate across cultural contexts and serve as a key conceptual framework to resolve ethical issues in a global context and as guidance in evaluating lower level moral norms. Therefore, hypernorms are created by a 'macro social contract' and represent the existence of the convergence of religious, cultural and philosophical belief around certain core principles of global relevance. However, the macro social contract entails 'moral free space' (Donaldson and Dunfee, 1994, p. 262) which allows the 
existence of community-specific 'micro social contracts' that prescribe moral norms relevant to local communities in addition to the hypernorms. However, it is noteworthy that, while communities may create peculiar community norms different from other communities, community norms are not supposed to conflict with hypernorms.

Social contracts theory, therefore, inherently recognizes the influence of time. Community norms are not static but they evolve over time. Micro social contracts will generally involve more norms as communities and cultures develop over time (Donaldson and Dunfee, 1999). Underdeveloped communities or cultures tend to leave the moral free space much more open. However, the moral free space can be filled in by newly developed community norms. Therefore, what used to be acceptable in a certain culture may become unacceptable under new community norms (Donaldson and Dunfee, 1994, 1999). For instance, bribing overseas government officials was not clearly perceived as illegal by Korean managers in the 1980s due to the absence of relevant laws, while it was for US managers after the Foreign Corrupt Practices Act (FCPA) was passed in the US in 1977 (Fritzsche et al., 1995).

\section{The evolution of ethical philosophy of Korean and US managers}

Following the initial attempt of Fritzsche and Becker (1984), a few studies have subsequently examined the link between ethical philosophy and ethical decision-making of US managers (e.g., Premeaux, 2004; Premeaux and Mondy, 1993; Whitcomb et al., 1998). More recently, Groves et al. (2008) reported the survey results of five vignettes based on the data collected from 200 US managers in the mid-2000s. By comparing their results with those of previous studies, Groves et al. (2008) concluded that US managers appear to be relatively more willing to adopt nonutilitarian philosophies, such as rights and justice ethical theories, for their ethical decisions, 
which are associated with enhanced moral reasoning and ethical decision-making. We compare the results of Fritzsche and Becker (1984) and Groves et al. (2008) to see the evolution of ethical philosophies employed by US managers for their ethical decision-making over the last two decades. Table 1 presents the proportion of respondents for each ethical philosophy across five ethical dilemmas. The general propensity is that US managers become much more dependent on rule utilitarianism and far less reliant on act utilitarianism. This tendency is substantially consistent with the finding of Forsyth et al.'s (2008) meta-analysis that US managers tend to have an exceptionist ethics whose outlook corresponds to a moral philosophy based on 'ruleutilitarianism.'

Insert Table 1 about Here

The development of community norms in the US over the last two decades may provide a rationale for such a tendency. A seemingly unending stream of highly publicized scandals in businesses, such as Enron, WorldCom and Tyco, has significantly increased needs and expectations of various stakeholders in the corporation's ethical and socially responsible behaviors (Ioannou and Serafeim, 2015; Snider, Hill, and Martin, 2003). Accordingly, a range of community norms such as social norms, national and corporate policies, laws and regulations, have been developed in the US and adopted by US firms over the last two decades, all of which provide a crucial source of ethical norms in business (Donaldson and Dunfee, 1999). These community norms inherently reflect the US's ethical position (i.e., exceptionism), representing less idealistic moral philosophies matching with well-documented individualism and less relativistic ethical theories affected by Judeo-Christian philosophies (Forsyth et al., 2008; 
Fritzsche et al., 1995). Consequently, US managers have become more dependent on such exceptionist ethics as rule-utilitarianism asserts.

Then how would ethical philosophies employed by Korean managers have evolved over the last two decades? By aggressively adopting the Western capitalist system during its rapid industrialization from the 1960s to the late 1980s, the Korean government pursued a rapid economic growth strategy to catch up with advanced Western economies (Amsden, 1992; Steinberg, 1989), and Korean firms, particularly large conglomerates (chaebols), have fully implemented the growth-oriented strategies primarily focusing on outcome-based growth (Kim, 1997; Wade, 1990). During this period, Korea has achieved remarkable economic growth, while it also created serious problems of business transparency and ethics (e.g., double accounting, cronyism, etc.) (Lee and Kim, 2014). It has been suggested that, for Korean managers, the most critical factor for managerial unethical decision-making was the political climate and the defective institutional environment, in other words, the absence of proper community norms to guide their behaviors (Christie et al., 2003).

After the Asian financial crisis in 1997, however, the Korean government began to push for the restructuring of business, and business ethics and corporate social responsibility have become an important agenda item in corporate governance. In particular, during the Participatory government regime led by President Roh Moo-Hyun from 2003 to 2008, the government vigorously sought to develop higher ethical standards by creating new regulations, legislation and policies. Facing the mounting pressures of these new policies, Korean firms, particularly those operating in the global arena, have spurred to establish codes of ethics and other ethical policies to run their business conforming to global standards of business ethics, which act as 'community norms' to their managers (Lee and Kim, 2014). 
Such community norms in Korea, however, have not developed in a vacuum. The Korean government and firms have largely transplanted or referred to the code of business ethics from the US and benchmarked the wide-ranging corporate ethical policies of US firms, both of which reflect the US's ethical position and moral ideology (Kim et al., 2013; Kim and Kim, 1997; You, 2015). This is partly due to the leading position of the US in business ethics and corporate social responsibility, which began to address business ethics issues and establish ethical climates in the 1970s earlier than any other capitalist nations (Vogel, 1992). But this is also, perhaps more, because of the strong link between Korea and the US, which has been continued over the last five decades since the Korea war (Kim, 1997). As the US has been the most significant political and economic partner for Korea, intensive interaction has developed between the two countries in the field of business and management. Korean firms have actively benchmarked the best practices and corporate policies from US firms (Bae and Rowley, 2003; Tung, Paik, and Bae, 2013). Benchmarking and learning from US practices, Korean firms began to deal with corporate social responsibility issues in more integrated and systematic ways, establishing organizational departments exclusively dealing with ethical regulations and compliance management with respect to human rights and environment issues (Chapple and Moon, 2005; Choi and Nakano, 2008; Lee and Kim, 2014; You, 2015).

Therefore, we contend that the community norms of Korean firms involve and reflect substantial elements of the US's ethical philosophy and moral ideology such as exceptionism and liberal individualism (Forsyth et al., 2008; Vogel, 1992). Accordingly, we predict a convergence of the ethical philosophies employed by Korean managers toward those of US managers, such that many Korean managers utilize more rule utilitarian philosophy compared to the previous two decades. Hypothesis 1 is formed as follow: 
Hypothesis 1: Korean managers utilize more rule utilitarian philosophy for ethical decisionmaking, compared to the past two decades.

\section{Balanced Thinking Style and Ethical Decision-Making of Korean Managers}

To understand the cognitive process through which managers make decisions concerning ethical dilemmas has increasingly become important in today's complex and globally competitive contexts (Groves et al., 2008). However, the empirical link between cognitive style, (or thinking style) and ethical decision-making has been largely overlooked, with few exceptions (e.g., Fleming, 1985; McIntyre and Capen, 1993; Pennino, 2002). Fleming (1985) made a significant contribution in explaining the relationship between thinking style and business ethics by demonstrating that decision-makers perceive and decide business problems, including ethical problems, in accordance with their thinking style. While it had been known that people with different thinking style differ in their information processing style, learning style, and decisionmaking style (e.g., Carlson and Levy, 1973; Lawrence, 1984), Fleming (1985) explicitly built a case for the contention that business ethical issues are an integral part of business problems, and therefore, decision-makers also apply their preferred thinking style to business ethical problems. Empirical literature on the link between cognitive style and business ethics has commonly utilized the Myers-Briggs Type Indicator (MBTI) to examine the relationship between a certain MBTI type (e.g., sensing vs. intuition, thinking vs. feeling) and ethical decision-making (e.g., McIntyre and Capen, 1993; McIntyre et al., 1995; White and Manolis, 1997), concluding that thinking style seems to trigger the formation of ethical ideologies, which further leads to the development of specific ethical stances. These studies usually sought to compare the different influence of linear (i.e., sensing/thinking) and nonlinear (i.e., intuition/feeling) elements in 
thinking style, on ethical decision-making.

More recently, however, Groves et al. (2008) underscored the importance of the balance between linear and nonlinear thinking style in making ethical decisions. Utilizing the Linear/Nonlinear Thinking Style Profile (LNTSP) developed by Vance et al. (2007), they demonstrated that managers utilizing a balanced linear/nonlinear thinking style tend to make more ethical decisions compared to managers with a predominantly linear or nonlinear thinking style. In line with the literature that has increasingly advocated thinking style models that capture both linear and nonlinear elements (Gaudine and Thorne, 2001; Parker and Stacey, 1994; Siggelkow and Rivkin, 2005), Groves et al. (2008, p. 307) proposed that managers with a balanced thinking style, defined as "the utilization of mental abilities that relies on both linear and nonlinear information processing", will proceed through Rest's (1986) four stages of ethical decision-making model (i.e., ethical awareness, judgment, intent and behavior), and thereby, demonstrate more ethical behavior, compared to those relying in a less complex sense on either linear or nonlinear thinking style when addressing ethical decisions. Groves et al. (2008) contends that individuals or managers who are receptive to nonlinear thinking sources such as feelings, emotions and intuitions are more likely to recognize the moral implications of a given dilemma, and thus, activate the first component of Rest's (1986) framework (i.e., recognizing ethical issues) (Sonenshein, 2007). Moreover, managers with the ability to 'feel' such emotions will formulate superior evaluative judgments and behavioral intent (Lurie, 2004). However, managers primarily relying on a linear thinking and decision-making style are prone to focus on cost-benefit analyses of the consequences of each alternative to an ethical dilemma, while they may not recognize the moral dimensions and ethical implications of a given problem due to insensitivity to nonlinear sources such as unpleasant gut feelings and emotions stemming from 
dealing with such a problem. On the contrary, a singular or an excessive reliance on nonlinear thinking sources and processes may also distort the ethical decision making process as it can lead to injudicious ethical decision-making without careful consideration of rational information sources such as company policies, professional and/or organizational codes of ethics, corporate values, and so on (Gaudine and Thorne, 2001; Klein, 2002; Lurie, 2004).

Overall, Groves et al. (2008) has discovered that American managers with a balanced thinking style are significantly more likely to make sound ethical decisions than managers with a dominant thinking style, either linear or non-linear. We predict that this finding would also be applicable to Korean managers. The four-stage model of ethical decision-making (Rest, 1986) is generally considered universally applicable to all individuals, irrespective of their national contexts. Thus, the theoretical argument of Groves et al. (2008) that both linear and nonlinear thinking styles are necessary for optimal moral judgment and ethical decision-making for any manager, and that individuals with a balanced thinking style tend to make ethical decisions is expected to be true with any individuals regardless of their national contexts including Korean managers. Therefore, hypothesis 2 is posited as following:

Hypothesis 2: Korean managers with a balanced linear/nonlinear thinking style will be more likely to make ethical decisions than managers with a predominantly linear or nonlinear thinking style.

\section{METHOD}

\section{Sample}

The sample consisted of 270 managers and business professionals from 16 different Korean companies of various sizes, across various industries including manufacturing, financial services, 
telecommunication, public services and professional services. The respondents' mean age was 37.87 years $(s . d .=7.96)$, and the sample consisted of 234 males $(86.7 \%)$ and 36 females (13.3\%). The respondents were all Korean nationals: $89 \%$ had attained at least an undergraduate college degree and 26\% had earned at least a master's level degree.

\section{Procedure}

To test our hypotheses, we conducted a survey in 2012 to collect data on Korean manager's thinking style and their managerial ethical decision-making along with their ethical philosophies. A carefully designed questionnaire was distributed to 400 fully-employed managers enrolled in three corporate MBA programs in large business schools in Seoul, Korea. The managers work at 16 different companies of various sizes (i.e., ranging from 50 to more than 10,000 employees) located in Korea. These managers were asked to complete the questionnaire in one week. Forty-

five returned questionnaires were incomplete and had to be discarded. The final sample $(\mathrm{n}=270)$ achieved an overall response rate of $68 \%$. To ensure the reliability and validity of the data, the Korean version of the questionnaire was cross-checked by bilingual researchers in Korea and pre-tested with 10 EMBA students and five managers who were studying in a short training program at a prestigious business school in Seoul, Korea. This process included a reverse translation of the English survey into Korean and back to English to ensure that the original meaning was not lost in the translation. All of the bilingual researchers discussed the questionnaire in detail to ensure that the Korean version was completely consistent with the English version and to avoid any ambiguity to the Korean respondents.

\section{Measures}


The Linear/Nonlinear Thinking Style Profile (LNTSP) developed by Vance et al. (2007) was adopted in this study. This profile shows strong convergent validity as well as strong external and face validity across student majors, managerial, and professional samples (Groves and Larocca, 2011; Groves et al., 2008). LNTSP consists of two sets of paired forced-choice items and corresponding scales of measurement. The item pairs are based upon the two complementary thinking styles: linear thinking as a preference for attending to and making decisions from external data, information, and facts; and nonlinear thinking as a preference for attending to and making decisions from internal feelings, impressions, and sensations. In the LNTSP, linear thinking style comprises external information source (EIS, eight items) and linear decisionmaking (LDM, five items) as subscales, whereas nonlinear thinking style includes internal information source (IIS, eight items) and nonlinear decision-making (NDM, five items) as subscales. The first set of forced-choice items includes five pairs of statements that describe alternative behaviors. Using a Likert-type scale ( 3 = "very often," 2 = "moderately often," $1=$ "occasionally," and $0=$ "rarely or never"), respondents were asked to allocate exactly three points across each pair of alternative statements according to how frequently they perform each behavior. An example of alternative pair statements includes "I primarily rely on feelings when making career decisions." and "I primarily rely on rationale when making career decisions." The second set of forced-choice items included eight paired words or phrases that influence behaviors. Using a Likert-type scale $(3$ = "very strong influence on how I behave," 2 = "strong influence on how I behave," 1 = "moderate influence on how I behave," and $0=$ little or no influence on how I behave") respondents were asked to allocate exactly three points across each pair of alternative words or phrases. Example items included "Feelings" and "Facts," and "Inner Knowing" and "Logical." (The entire set of items for EIS, IIS, LDM, and NDM is presented in 
the appendix).

\section{Managerial ethical decision-making}

Fritzsche and Becker's (1984) five vignettes were adapted to the Korean context to measure managerial ethical intent across the following ethical dilemmas: (i) coercion and control, (ii) conflict of interest, (iii) physical environment, (iv) paternalism, and (v) personal integrity. These series of five vignettes have been frequently utilized in many prior studies on managerial ethical intent and business ethics (e.g., Groves et al., 2008; Premeaux and Mondy, 1993; Premeaux, 2004). After reading the vignette, respondents were asked to assume the role of the decisionmaker and offer two responses: (a) how they would resolve the ethical dilemma by indicating on a scale of 0-10 (0= "definitely would not," $10=$ "definitely would") the likelihood of responding to a behavior of questionable morality (e.g., agreeing to bribery as a means of coercion); and (b) the rationale for their decision to resolve each ethical dilemma. The rationales for each ethical dilemma, offered as response categories, represent a range of ethical theories. For example, the question following the coercion and control dilemma (vignette 1) was "Would you pay the price of $\$ 500,000$ ?” which represented a bribe to allow expansion into a foreign market. After indicating their degree of willingness to accept the bribe on a 0 to 10 scale, respondents stated the rationale for their decision across the following categories: (a) against company policy, (b) illegal, (c) bribe, unethical, (d) no one is hurt, (e) is an acceptable practice in other countries, (f) is not unethical, (g) just the price paid to do business, and (h) other (qualitative response). For vignette 1 , responses (a), (b), and (c) represent rule utilitarianism and responses (d), (e), (f) and (g) represent act utilitarianism, while there is no response representing rights and justice theories. 
(See Fritzsche and Becker (1984) for the original survey including all five vignettes and the rationales for the responses).

\section{RESULTS}

Table 2 presents the descriptive statistics and correlations. It shows means and standard deviation of respondents' ethical decision-making across five vignettes and those of LNTSP dimensions. The EIS and IIS dimensions and the LDM and NDM dimensions demonstrated negative relationships. Moreover, EIS was positively correlated to LDM and IIS was positively associated with NDM. These relationships among the LNTSP dimensions are expected and natural as individuals who tend to adopt either a linear or nonlinear preference for information sources are also likely to prefer a corresponding linear or nonlinear approach to processing information for decision-making (Groves et al., 2008; Vance et al., 2007).

Insert Table 2 about Here

\section{The evolution of ethical philosophy of Korean managers}

Table 3 presents our results of Korean managers' responses to five ethical dilemmas, along with the results from Fritzsche et al. (1995) that conducted the same survey with 83 Korean managers during the 1990s. Consistent with previous studies that conducted the same survey (e.g., Groves et al., 2008; Premeaux, 2004), Korean managers predominantly use utilitarian philosophies rather than deontological philosophies such as rights and justice theories. However, as hypothesized, the proportion of act and rule utilitarianism employed by Korean managers in 2012 reveals significant changes compared to the results presented in 1995. For the 'control and 
coercion' problem, Korean managers still predominantly base their ethical decision on act utilitarianism, but $20 \%$ of respondents used rule utilitarianism. This is a substantial increase considering that there were only $4 \%$ of respondents who used rule utilitarian philosophy in 1995 . The results demonstrated the overall change of ethical philosophy used by Korean managers in the 'conflict of interest' problem. We also observed a significant increase of Korean managers utilizing rule utilitarian philosophy, together with a considerable decrease in using act utilitarianism. For the 'physical environment' issue, we also found a large increase of Korean managers utilizing rule utilitarian philosophy, although nearly half of the respondents use act utilitarianism to make ethical decisions concerning environment. For the 'paternalism' problem, Korean managers did not show much change in their use of rule utilitarianism, while a significant proportion of respondents utilize act utilitarianism compared to 1995 . Finally, for the 'personal integrity' issue, Korean managers disclose a significant preference for the rights theory, compared to the past two decades, even though many of them still seem to utilize act utilitarianism for this issue. In summary, although the degree of change in responses to different ethical dilemmas varies, we found a growing trend of Korean managers utilizing more rule utilitarian philosophy across all ethical dilemmas except for the 'paternalism' problem. Therefore, overall, the results lend support to hypothesis 1 .

Insert Table 3 about Here

\section{Balanced Thinking Style and Ethical Decision-Making of Korean Managers}

Overall linear thinking style was calculated by combining the EIS and LDM scores, while overall nonlinear thinking style was calculated by adding the IIS and NDM scores (Groves et al., 
2008). Cronbach alpha reliability estimates were 0.847 for both linear and nonlinear thinking styles (13 items respectively). Next, we calculated the arithmetic difference by subtracting participants' overall nonlinear thinking style scores from their overall linear thinking style scores. Therefore, the participants can, in principle, have any score between -39 to 39 depending on their thinking style: a positive difference score (i.e., 1 to 39) indicates a preference for linear thinking while a negative difference score (i.e., -39 to -1) indicates a preference for nonlinear thinking. Scores in both extremes indicate the strong propensity for having either linear or nonlinear thinking style, whereas scores in the middle (i.e., around zero) display a balanced linear/nonlinear way of thinking. In our analysis, the mean score of arithmetic difference between Korean managers' linear and nonlinear thinking style was 10.3, indicating a general tendency that Korean managers have a strong linear thinking style rather than a nonlinear one. Following previous studies (e.g., Groves et al., 2008; Vance, Groves, and Choi, 2006), we have assigned participants that have a difference score greater than 10 into the linear thinking style group, and those with less than -10 into the nonlinear thinking style group. Participants with the score between 10 and -10 have been classified into the balanced thinking style group. This process has assigned our 270 Korean managers into 144 linear thinkers (53\%), 7 nonlinear thinkers (2.5\%), and 119 balanced thinkers (44\%).

Hypothesis 2 predicted that managers with a balanced thinking style would demonstrate a lower propensity to commit unethical behaviors than managers with either a predominantly linear or nonlinear thinking style. Table 4 presents the results from Tukey's honestly significant difference (HSD) test across the mean response of three different thinking groups' ethical decisions to each vignette. Overall, the analysis did not reveal any significant differences among the different types of thinkers across all five vignettes. Although the ANOVA and the post-hoc t- 
test has revealed that managers with a more balanced way of thinking have slightly more ethical behavior intents in vignette $2(\mathrm{p}<0.10)$, we found no statistically significant mean differences in other vignettes. Therefore, hypothesis 2 was rejected.

Insert Table 4 about Here

\section{DISCUSSION}

\section{Theoretical implications}

This study examines the influence of ethical philosophy and thinking style on ethical decision-making in the Korean context. The first objective of this research was to explore whether cross-cultural differences in ethical decision-making remain over time or not. Although many scholars have investigated the influence of culture and time on international business ethics, we know little about whether the national differences in business ethics remain unchanged or disappear over time. More importantly, little is known about the mechanism of such evolution. This study intends to fill these research gaps by examining how the ethical philosophies employed by Korean managers have evolved over the last two decades.

We built on social contracts theory (Donaldson and Dunfee, 1994, 1999) to develop a convergence hypothesis on the evolution of ethical philosophies adopted by Korean managers. We theorize that strong economic and political ties between Korea and the US, and the related intensive interaction between the two countries have influenced the community norms developed in Korea, such as codes of ethics and ethical standards over the past two decades. After the Asian financial crisis in 1997, both Korean government and firms sought to enhance their standards of 
business ethics conforming to the global standard. During this period, they benchmarked the US standard, adopting or consulting from the US-developed codes of business ethics, company policies related to corporate social responsibility, and compliance management pertaining to human rights and environment issues (Lee and Kim, 2014; You, 2015). Therefore, community norms governing Korean managers may have involved or reflected substantial elements of ethical philosophy and moral ideology of US firms and managers. As a result, Korean managers may have become more reliant on rule utilitarian philosophy, similar to US managers, compared to the past. In general, we observed the supporting results from our survey data.

One may question such asymmetric influence between two countries: why does the US mainly affect the development of community norms in Korea and not vice versa? Indeed, the cross-cultural influence and interaction are inherently asymmetrical (Håkanson et al., 2016; Shenkar, 2001). Through the process of globalization and lively interchanges between the East and the West, cultures influence each other and change (Leung et al., 2005). National cultures and traditional value systems change over time, but the degree of cultural changes is not identical among cultures depending on many aspects such as economic development and the broad cultural heritage of society (Inglehart and Baker, 2000). Given the different socio-cultural contexts, unique historical background, and economic development level (Amsden, 1992; Kim, 1997), the influence of the interaction between Korea and the US is not symmetrical. Håkanson and Ambos (2010) presented empirical evidence for the existence of such asymmetries in terms of psychic distance between the managers of two countries: the perceived psychic distance of Korean managers to the U.S. was almost the lowest among 25 countries in the sample, equivalent to the distances to China and Japan, whereas the perceived psychic distance of American managers to Korea was almost the highest level, more than three times higher than that of 
Korean managers to the US. Certainly, many studies have reported that Korean firms have actively adopted the best practices and corporate policies from US firms over the last few decades, whereas the opposite case has just recently begun (Tung et al., 2013). In particular, before the Asian financial crisis, Korean firms had been largely influenced by Japanese firms' business practices, but after the crisis, US practices gained legitimacy as being more advanced and effective, and have been introduced and adopted widely in Korea (Bae and Rowley, 2003; Chung, Sparrow, and Bozkurt, 2014). Therefore, we believe such influences from US firms and policies have largely affected the community norms developed in Korea over the last two decades, which results in a convergence of ethical philosophy between Korean and American managers.

This study, therefore, contributes to international business ethics research by presenting a theoretical framework that may explain the convergence of ethical philosophies utilized by managers in different national contexts. International business scholars have called for more attention to examining the boundaries between convergence and divergence in individual behaviors, attitudes and beliefs (e.g., Kelley et al., 1987; Parboteeah and Cullen, 2003). Similarly, DeGeorge (1993, p. 11) argued that the focus on divergence in international business ethics literature needs to be tempered with the research of convergence, by noting that "basic morality does not vary from country to country, even though certain practices may be ethical in one country and not in another because of differing circumstances." In an increasingly globalized world of business, the identification of cultural similarity or convergence is recognized just as important as that of differences, because individuals of different countries and societies need to build on common morality and beliefs when working or interacting together (Bailey and Spicer, 
2007; Boyacigiller and Adler, 1991; Leung et al., 2005). By responding to these calls, this research enhances our understanding of convergence in international business ethics.

The second objective of this study was to reexamine the finding of Groves et al. (2008) derived from US data, that managers utilizing a balanced linear and nonlinear thinking style show a greater overall willingness to make ethical decisions, in the Korean context. Our results showed that Korean managers with a balanced thinking style do not appear to make more ethical decisions than those with a predominantly linear or nonlinear thinking style. It is argued that balanced thinkers may scrutinize a given ethical alternative making use of its emotional and intuitive value as well as its consistency with more linear information sources, such as company policy, codes of conduct, and relevant 'hard' data (Lurie, 2004), and hence, they are more able to make optimal moral reasoning and ethical decisions (Groves et al., 2008). However, our results of Korean managers imply that balanced thinkers do not always make more ethical decisions compared to linear/nonlinear thinkers.

Groves et al. (2008) reported that balanced thinkers in the US sample have a strong tendency to avoid act utilitarianism that is commonly associated with significantly more unethical decision-making (Fritzsche and Becker, 1984; Fritzsche et al., 1995; Groves et al., 2008; Premeaux, 2004). On the contrary, we found that Korean managers with a balanced thinking style did not demonstrate any significant difference in adopting act utilitarian philosophy, compared to those with predominantly linear thinking style. In fact, both balanced and linear thinker groups in the Korean context have almost equally exercised act utilitarianism for their ethical decision-making, which, we believe, results in no significant differences in their overall decision-making practices. 
Our finding implies that a balanced thinking style does not always lead to more ethical decision-making. Groves et al. (2008) suggested that balance thinkers' receptivity to and processing of both linear and nonlinear information sources may facilitate consideration of several alternative ethical philosophies other than act utilitarianism that mainly focuses on the consequences or outcomes of a decision. However, we suspect that such positive influence of balanced thinking style may not necessarily appear in other national contexts with different ethical positions. US managers may commonly have an 'exceptionists ethics' whose outlook corresponds to rule utilitarianism (Forsyth, 1992; Forsyth et al., 2008). Therefore, the positive influence of utilizing balanced thinking style may have emerged in the US context as explained by Groves et al. (2008). However, such influence of balanced thinking style may not be so significant in the Korean context where managers tend to have a situationists ethics which corresponds to situation ethics, value pluralism or act utilitarianism (Forsyth, 1992; Forsyth et al., 2008). Nevertheless, Korean managers tend to utilize more rule utilitarian philosophy for their ethical decision-making than the past two decades, yet a considerable number of Korean managers still rely on act utilitarianism, particularly compared to US managers.

In summary, our findings contribute to the existing knowledge of the cognitive basis of managerial ethics by suggesting that the influence of thinking style on the ethical decisionmaking may not be uniform across countries. We demonstrate that the relationship between thinking style and ethical decision-making may not be universal, but contingent on a national context.

\section{Managerial Implications}


This study provides important implications for both policy-makers and firms in Korea. Consistent with previous literature, we also found that managers utilizing act utilitarianism for their ethical decision-making tend to make significantly more unethical managerial decisions. Table 5 shows the detailed results of our analysis about the ethical philosophies and ethical decision-making of Korean managers across five ethical dilemmas. Across all five ethical problems, managers adopting rule utilitarianism demonstrated a significantly greater willingness to make ethical decisions, compared to those with act utilitarianism $(\mathrm{p}<0.001)$.

Insert Table 5 about Here

This finding provides a useful direction for policy-makers and firms that strive to enhance their business ethical standards and promote ethical behaviors among their managers. We believe that the development of community norms and business ethical education that induce managers to avoid act utilitarianism would be effective. For instance, firms may develop community norms and design their training programs in ways to encourage their managers to understand the benefits of abiding by the rules and promoting justice in the long run.

Moreover, the result of a different proportion of ethical philosophies employed by Korean managers across ethical dilemmas suggests that both policy-makers and firms should place more emphasis on establishing community norms with respect to overseas bribery and environment issues. Our results, compared with those of Groves et al. (2008), show that Korean managers utilized very similar ethical philosophies to US managers in dealing with the ethical dilemmas related to 'conflicts of interest', 'paternalism', and 'personal integrity'. However, Korean managers still have a strong penchant for act utilitarianism with respect to the ethical dilemmas 
of 'coercion and control' and 'physical environment.' A possible explanation for this result is the Korean manager's strong tendency for collectivist behavior in the sense that they act according to their company interests (Choi and Nakano, 2008). Korean managers tend to have a dual ethical standard, one for their personal life and another for their professional life, and they are prone to accept an incompatibility of business and ethics, while most of US managers disagree with it (Choi and Nakano, 2008; Christie et al., 2003). Therefore, confronting the ethically dilemmatic business situation that accompanies an obvious economic benefit for the company, Korean managers tend to make decisions based on situationism or act utilitarianism for their company interests. Another plausible explanation can be attributed to less strict and incomplete community norms, such as legal system and government enforcement, regarding those two dilemmas. The American FCPA explicitly prohibits the bribing of foreign officials, while corresponding regulation and enforcement are much less strict in Korea (Choi and Nakano, 2008; Kim and Kim, 1997). With regard to the physical environment issue, Korea, like most developing countries, adopted 'grow first, clean up later' environmental policies during its rapid economic development (Aden, Ahn, and Rock, 1999; Eder, 1996). More rigorous environmental business standards and legislation were enacted only beginning in the 2000s (Lee and Kim, 2014). Therefore, Korean managers seem to accept relatively weak environment-related community norms, compared to US managers. Considering that Korean managers using rule utilitarian philosophy make certainly more ethically sound decisions in both problems, we believe this finding should encourage them to pay more attention to developing more rigorous community norms concerning overseas bribery and environment problems.

\section{Limitation and Future Research Directions}


This study has several limitations and suggestions for future research. To begin with, we collected our data on Korean managers' ethical decision-making using Fritzsche and Becker's (1984) vignette. Therefore, our research is not free from commonly addressed limitations concerning this method, such as social desirability issue and utilizing intentions instead of actual behaviors (Fritzsche and Becker, 1984; Fritzsche et al., 1995). However, the threat of socially desirable responses is likely minimal because none of the standard responses to the vignettes could be reasonably considered ethically safe or socially acceptable (Groves et al., 2008). Moreover, literature has demonstrated that intentions can be reliable predictors of behaviors in high involvement context such as ethical dilemmas (Ajzen and Fishbein, 1977).

Second, we collected the data for both thinking style and ethical decision-making variables through the same survey; hence, the links between these variables are subject to common method bias. However, we believe that our questionnaire was designed to minimize potential common method bias as the measures for thinking style and ethical decision-making were placed at different positions in the survey with different scale anchors (Salancik and Pfeffer, 1977). Moreover, it was very unlikely that respondents could map hypothesized relations between constructs from the flow of the survey, thereby diminishing social desirability bias.

Third, this study demonstrated that a balanced linear and nonlinear thinking style does not always generate more ethical decision-making, at least in the Korean context. This was an unexpected result, conflicting with previous study in the US context, but it strongly suggests that there is another area that requires further investigation. An important agenda for future research is to identify the mechanism underlying the link between thinking style and ethical philosophies. Groves et al. (2008, p. 316) explicitly noted that "balanced thinkers were 'unexpectedly' least likely to adopt an act utilitarian philosophy" in the US context. Indeed, their survey results across 
vignettes seem to support that an inclination of balanced thinkers to avoid act utilitarianism is the key for the positive relationship between balanced thinking style and ethical decision-making. However, we did not detect such a tendency in the Korean context, and we suppose this is the main cause for the conflicting result. Therefore, future studies unraveling the link between thinking style and ethical philosophies will greatly enhance our understanding of the cognitive basis of business ethics.

Finally, our research resonates with calls from the literature for more attention to examining convergence and divergence in international business ethics (Bailey and Spicer, 2007; DeGeorge, 1993). Given the increasingly globalized nature of the business world, identifying the boundaries of convergence in managerial ethics constitutes an important subject of future research. In particular, investigating how well-documented national differences in international business ethics evolve over time from the perspective of convergence and divergence will provide deeper insight into contemporary business ethics in a global context. 
Table 1. Comparison of US managers' ethical philosophy for responses to ethical dilemmas (1984 vs. 2008)

\begin{tabular}{|c|c|c|c|c|c|c|c|c|c|c|}
\hline \multirow{2}{*}{$\begin{array}{l}\text { Ethical } \\
\text { Ethical }\end{array}$} & \multicolumn{2}{|c|}{$\begin{array}{c}\text { Vignette } 1 \\
\text { (coercion and control) }\end{array}$} & \multicolumn{2}{|c|}{$\begin{array}{c}\text { Vignette } 2 \\
\text { (conflict of interest) }\end{array}$} & \multicolumn{2}{|c|}{$\begin{array}{c}\text { Vignette } 3 \\
\text { (physical environment) }\end{array}$} & \multicolumn{2}{|c|}{$\begin{array}{c}\text { Vignette } 4 \\
\text { (paternalism) }\end{array}$} & \multicolumn{2}{|c|}{$\begin{array}{c}\text { Vignette } 5 \\
\text { (personal integrity) }\end{array}$} \\
\hline & 1984 & 2008 & 1984 & 2008 & 1984 & 2008 & 1984 & 2008 & 1984 & 2008 \\
\hline Right & - & 8 & 21 & 16 & - & 7 & - & 1 & 64 & 82 \\
\hline Justice & - & 8 & - & 3 & 16 & 19 & - & 3 & - & 2 \\
\hline Act Utilitarianism & 41 & 16 & 36 & 9 & 45 & 25 & 30 & 17 & 18 & 7 \\
\hline Others & 10 & 11 & 7 & 2 & 15 & 2 & 13 & 3 & 8 & 5 \\
\hline EDM Mean & 4.00 & 2.85 & 3.9 & 2.79 & 0.6 & 1.76 & 2.8 & 2.17 & 7.7 & 7.84 \\
\hline
\end{tabular}

Note: EDM (Ethical Decision-making), The entries are proportion (\%) of responses to the vignettes from Fritzsche and Becker (1984). The responses for 1984 are presented by Fritzsche and Becker (1984) based on data from 124 US managers (The mean age of the respondents was 43 years and the sample consisted of $81 \%$ males)

The responses for 2008 are presented by Groves et al. (2008) based on data from 200 US managers (The mean age of the respondents was 37 years and the sample consisted of 55\% males) 
Table 2. Descriptive statistics and correlations across ethical decisions and LNTSP dimensions

\begin{tabular}{|c|c|c|c|c|c|c|c|c|c|c|}
\hline & Mean & S.D. & V1 & $\mathrm{V} 2$ & V3 & V4 & V5 & EIS & IIS & LDM \\
\hline Vignette 1 (Coercion and Control) & 4.34 & 3.37 & - & & & & & & & \\
\hline Vignette 2 (Conflict of Interest) & 3.74 & 2.92 & $0.19^{* *}$ & - & & & & & & \\
\hline Vignette 3 (Physical Environment) & 2.19 & 2.62 & $0.28^{* *}$ & $0.34^{* *}$ & - & & & & & \\
\hline Vignette 4 (Paternalism) & 3.80 & 3.74 & $0.16^{* *}$ & $0.22^{* *}$ & $0.16^{*}$ & - & & & & \\
\hline Vignette 5 (Personal Integrity) & 7.06 & 3.22 & -0.05 & -0.03 & -0.10 & -0.09 & - & & & \\
\hline External Information Source (EIS) & 1.92 & 0.39 & -0.02 & $0.12^{*}$ & 0.03 & 0.01 & -0.05 & & & \\
\hline Internal Information Source (IIS) & 1.08 & 0.39 & 0.02 & $-0.12^{*}$ & -0.03 & -0.01 & 0.05 & $-1.00^{* *}$ & & \\
\hline Linear Decision-making (LDM) & 1.85 & 0.43 & 0.02 & $0.15^{*}$ & -0.01 & 0.01 & -0.01 & $0.63^{* *}$ & $-0.63^{* *}$ & \\
\hline (Nonlinear Decision-making (NDM) & 1.15 & 0.43 & -0.02 & $-0.15^{*}$ & 0.01 & -0.01 & 0.01 & $-0.63^{* *}$ & $0.63^{* *}$ & $-1.00^{* *}$ \\
\hline
\end{tabular}

Note: $\mathrm{N}=270, * \mathrm{p}<0.05, * * \mathrm{p}<0.01$, Vignettes are adopted from Fritzsche and Becker (1984). 
Table 3. Comparison of Korean managers' ethical philosophy for responses to ethical dilemmas (1995 vs. 2012)

\begin{tabular}{|c|c|c|c|c|c|c|c|c|c|c|}
\hline Dilemical & $\begin{array}{r}\mathrm{Vi} \\
\text { (coercio }\end{array}$ & $\begin{array}{l}1 \\
\text { control) }\end{array}$ & $\begin{array}{r}\mathrm{Vi} \\
\text { (conflic }\end{array}$ & $\begin{array}{l}\text { eterest) } \\
\text { inter }\end{array}$ & $\begin{array}{r}\mathrm{V} \\
\text { (physica }\end{array}$ & $\begin{array}{l}3 \\
\text { onment) }\end{array}$ & $\begin{array}{r}\text { Viq } \\
\text { (pate }\end{array}$ & $\begin{array}{l}\text { te } 4 \\
\text { lism) }\end{array}$ & $\begin{array}{r}\mathrm{Vi} \\
\text { (persor }\end{array}$ & te 5 \\
\hline Philosophy & 1995 & 2012 & 1995 & 2012 & 1995 & 2012 & 1995 & 2012 & 1995 & 2012 \\
\hline Right & - & - & 2 & 14 & - & - & - & - & 27 & 52 \\
\hline Justice & - & - & - & - & 20 & 21 & - & - & - & - \\
\hline Act Utilitarianism & 73 & 67 & 60 & 26 & 32 & 46 & 12 & 32 & 27 & 38 \\
\hline Others & 23 & 12 & 22 & 4 & 43 & 2 & 22 & 6 & 43 & 1 \\
\hline EDM Mean & 4.2 & 4.34 & 5.2 & 3.74 & 3.5 & 2.19 & 2.7 & 3.8 & 6.8 & 7.06 \\
\hline
\end{tabular}

Note: EDM (Ethical Decision-making), The entries are proportion (\%) of responses to the vignettes from Fritzsche and Becker (1984). The responses for 1995 are presented by Fritzsche et al. (1995) based on data from 83 Korean managers (The mean age of the respondents was 35 years and the sample consisted of $78 \%$ males)

The responses for 2012 are collected by the authors from 270 Korean managers (The mean age of the respondents was 38 years and the sample consisted of $86 \%$ males) 
Table 4. Tukey's HSD test results comparing balanced, linear, and nonlinear thinking style profile differences across mean scores of Vignette ethical decisions

\begin{tabular}{ccccccc}
\hline & \multicolumn{3}{c}{ Balanced vs. Linear Thinkers } & & \multicolumn{2}{c}{$\begin{array}{c}\text { Balanced vs. Nonlinear } \\
\text { Thinkers }\end{array}$} \\
\cline { 2 - 4 } \cline { 6 - 7 } & $\begin{array}{c}\text { Balanced } \\
\text { Mean }\end{array}$ & $\begin{array}{c}\text { Linear } \\
\text { Mean }\end{array}$ & $\begin{array}{c}\text { Mean } \\
\text { difference }\end{array}$ & & $\begin{array}{c}\text { Nonlinear } \\
\text { Mean }\end{array}$ & $\begin{array}{c}\text { Mean } \\
\text { difference }\end{array}$ \\
\hline Vignette 1 & 4.39 & 4.39 & 0 & & 2.57 & 1.82 \\
Vignette 2 & 3.39 & 4.08 & -0.69 & & 2.57 & 0.82 \\
Vignette 3 & 2.25 & 2.15 & 0.10 & & 2.00 & 0.25 \\
Vignette 4 & 3.72 & 3.90 & -0.18 & & 3.29 & 0.43 \\
Vignette 5 & 7.06 & 7.03 & 0.03 & & 8.14 & -1.08 \\
\hline
\end{tabular}

Note: $\mathrm{N}=270$, Balanced Thinker $(\mathrm{n}=119)$, Linear Thinker $(\mathrm{n}=144)$, Nonlinear Thinker $(\mathrm{n}=7)$ 
Table 5. Korean managers' ethical philosophy and ethical decision-making

\begin{tabular}{|c|c|c|c|c|c|c|c|c|c|c|}
\hline $\begin{array}{r}\text { Ethical } \\
\text { Dilemma }\end{array}$ & $\begin{array}{r}\mathrm{Vi} \\
\text { (coercio }\end{array}$ & $\begin{array}{l}\text { te } 1 \\
\text { d control) }\end{array}$ & $\begin{array}{r}\mathrm{Vi} \\
\text { (conflic }\end{array}$ & $\begin{array}{l}\text { tte } 2 \\
\text { interest) }\end{array}$ & $\begin{array}{r}\mathrm{V} \\
\text { (physica }\end{array}$ & $\begin{array}{l}\text { e } 3 \\
\text { ronment) }\end{array}$ & $\begin{array}{r}\text { Vig } \\
\text { (pate }\end{array}$ & $\begin{array}{l}\text { tte } 4 \\
\text { alism) }\end{array}$ & $\begin{array}{r}\mathrm{Viq} \\
\text { (person }\end{array}$ & $\begin{array}{l}\text { tte } 5 \\
\text { ntegrity) }\end{array}$ \\
\hline $\begin{array}{l}\text { Ethical } \\
\text { Philosophy }\end{array}$ & Count & $\begin{array}{c}\text { EDM } \\
\text { (Mean) }\end{array}$ & Count & $\begin{array}{c}\text { EDM } \\
\text { (Mean) }\end{array}$ & Count & $\begin{array}{c}\text { EDM } \\
\text { (Mean) }\end{array}$ & Count & $\begin{array}{c}\text { EDM } \\
\text { (Mean) }\end{array}$ & Count & $\begin{array}{c}\text { EDM } \\
\text { (Mean) }\end{array}$ \\
\hline Justice & - & - & - & - & 57 & 1.67 & - & - & - & - \\
\hline Rule Utilitarianism & 58 & 1.43 & 150 & 2.83 & 83 & 0.51 & 166 & 1.50 & 23 & 2.78 \\
\hline Others & 32 & 3.78 & 11 & 5.55 & 6 & 2.33 & 17 & 6.53 & 4 & 7.50 \\
\hline Total & 270 & 4.34 & 270 & 3.74 & 270 & 2.19 & 270 & 3.80 & 270 & 7.06 \\
\hline
\end{tabular}

Note: EDM (Ethical Decision-making), The entries are responses to the vignettes from Fritzsche and Becker (1984).

(1) Higher EDM scores indicate a greater likelihood of responding to the ethical dilemmas with an unethical response except for vignette 5 (personal integrity). Higher EDM scores for vignette 5 indicate a greater likelihood of ethical response.

(2) Tukey's HSD test showed that the EDM (mean) differences between Rule Utilitarianism and Act Utilitarianism responses were significant at $\mathrm{p}<0.001$ throughout all five vignettes. 


\section{REFERENCES}

Abramson, N. R., Keating, R. J., \& Lane, H. W. (1996). Cross-national cognitive process differences: A comparison of Canadian, American and Japanese managers. MIR: Management International Review, 123-147.

Aden, J., Ahn, K.-H., \& Rock, M. T. (1999). What is driving the pollution abatement expenditure behavior of manufacturing plants in Korea? World Development, 27(7), 1203-1214.

Ajzen, I., \& Fishbein, M. (1977). Attitude-behavior relations: A theoretical analysis and review of empirical research. Psychological Bulletin, 84(5), 888-918.

Alderson, S., \& Kakabadse, A. (1994). Business ethics and Irish management: a cross-cultural study. European Management Journal, 12(4), 432-441.

Alexander, C. S., \& Becker, H. J. (1978). The use of vignettes in survey research. Public opinion quarterly, 42(1), 93-104.

Allinson, C. W., \& Hayes, J. (1996). The cognitive style index: A measure of intuition-analysis for organizational research. Journal of Management Studies, 33(1), 119-135.

Allinson, C. W., \& Hayes, J. (2000). Cross-national differences in cognitive style: implications for management. International Journal of Human Resource Management, 11(1), 161-170.

Amsden, A. H. (1992). Asia's next giant: South Korea and late industrialization. Oxford, UK: Oxford University Press.

Armstrong, R. W., Stening, B. W., Ryans, J. K., Marks, L., \& Mayo, M. (1990). International marketing ethics: problems encountered by Australian firms. European Journal of Marketing, 24(10), 5-18.

Bae, J., \& Rowley, C. (2003). Changes and continuities in South Korean HRM. Asia Pacific Business Review, 9(4), 76-105.

Bailey, W., \& Spicer, A. (2007). When does national identity matter? Convergence and divergence in international business ethics. Academy of Management Journal, 50(6), 1462-1480.

Barry, V. E. (1979). Moral issues in business. Belmont, CA: Wadsworth.

Bartels, R. (1967). A model for ethics in marketing. Journal of Marketing, 31(1), 20-26.

Beauchamp, T. L., \& Bowie, N. E. (1979). Ethical Theory and Business. Englewood Cliffs, NJ: Prentice-Hall.

Becker, H., \& Fritzsche, D. J. (1987). A Comparison of the Ethical Behavior of American, French and German Languages. Columbia Journal of World Business, 22(4), 87-95.

Boyacigiller, N. A., \& Adler, N. J. (1991). The parochial dinosaur: Organizational science in a global context. Academy of Management Review, 16(2), 262-290.

Carlson, R., \& Levy, N. (1973). Studies of Jungian typology: I. Memory, social perception, and social action. Journal of Personality, 41(4), 559-576.

Cavanagh, G. F., Moberg, D. J., \& Velasquez, M. (1981). The ethics of organizational politics. Academy of Management Review, 6(3), 363-374.

Chapple, W., \& Moon, J. (2005). Corporate social responsibility (CSR) in Asia a seven-country study of CSR Web site reporting. Business and Society, 44(4), 415-441. doi:10.1177/0007650305281658

Choi, T. H., \& Nakano, C. (2008). The evolution of business ethics in Japan and Korea over the last decade. Human Systems Management, 27(3), 183-199. 
Christie, P. M. J., Kwon, I.-W. G., Stoeberl, P. A., \& Baumhart, R. (2003). A cross-cultural comparison of ethical attitudes of business managers: India Korea and the United States. Journal of Business Ethics, 46(3), 263-287.

Chung, C., Sparrow, P., \& Bozkurt, Ö. (2014). South Korean MNEs’ international HRM approach: Hybridization of global standards and local practices. Journal of World Business, 49(4), 549-559.

DeGeorge, R. T. (1993). Competing with integrity in international business. New York: Oxford University Press.

Donaldson, T., \& Dunfee, T. W. (1994). Toward a unified conception of business ethics: Integrative social contracts theory. Academy of Management Review, 19(2), 252-284.

Donaldson, T., \& Dunfee, T. W. (1999). Ties that bind: A social contracts approach to business ethics. Boston, MA: Harvard Business Publishing.

Dubinsky, A. J., Jolson, M. A., Kotabe, M., \& Lim, C. U. (1991). A cross-national investigation of industrial salespeople's ethical perceptions. Journal of International Business Studies, 22(4), 651-670.

Eder, N. R. (1996). Poisoned prosperity: development, modernization, and the environment in South Korea. New York: ME Sharpe.

Fleming, J. E. (1985). A suggested approach to linking decision styles with business ethics. Journal of Business Ethics, 4(2), 137-144.

Fletcher, J. F. (1966). Situation ethics: The new morality: Westminster John Knox Press.

Forsyth, D. R. (1980). A taxonomy of ethical ideologies. Journal of personality and social psychology, 39(1), 175-184.

Forsyth, D. R. (1992). Judging the morality of business practices: The influence of personal moral philosophies. Journal of Business Ethics, 11(5), 461-470.

Forsyth, D. R., O’boyle, E. H., \& McDaniel, M. A. (2008). East meets west: A meta-analytic investigation of cultural variations in idealism and relativism. Journal of Business Ethics, 83(4), 813-833.

Fritzsche, D. J., \& Becker, H. (1984). Linking management behavior to ethical philosophy-An empirical investigation. Academy of Management Journal, 27(1), 166-175.

Fritzsche, D. J., Huo, Y. P., Sugai, S., Tsai, S. D.-H., Kim, C. S., \& Becker, H. (1995). Exploring the ethical behavior of managers: A comparative study of four countries. Asia Pacific Journal of Management, 12(2), 37-61.

Gaudine, A., \& Thorne, L. (2001). Emotion and ethical decision-making in organizations. Journal of Business Ethics, 31(2), 175-187.

Ghemawat, P. (2001). Distance still matters. Harvard Business Review, 79(8), 137-147.

Ghemawat, P. (2007). Redefining global strategy. Boston: Harvard Business School Publishing.

Groves, K., Vance, C., \& Paik, Y. (2008). Linking linear/nonlinear thinking style balance and managerial ethical decision-making. Journal of Business Ethics, 80(2), 305-325.

Gupta, V., \& Wang, J. (2004). The transvergence proposition under globalization: Looking beyond convergence, divergence and crossvergence. Multinational Business Review, 12(2), 37-58.

Hall, E. T., \& Hall, M. R. (1987). Hidden differences: Doing business with the Japanese. New York: Anchor Books.

Håkanson, L., \& Ambos, B. (2010). The antecedents of psychic distance. Journal of International Management, 16(3), 195-210. 
Håkanson, L., Ambos, B., Schuster, A., \& Leicht-Deobald, U. (2016). The psychology of psychic distance: Antecedents of asymmetric perceptions. Journal of World Business, 51(2), 308-318.

Honeycutt, E. D., Siguaw, J. A., \& Hunt, T. G. (1995). Business ethics and job-related constructs: A cross-cultural comparison of automotive salespeople. Journal of Business Ethics, 14(3), 235-248.

Inglehart, R., \& Baker, W. E. (2000). Modernization, cultural change, and the persistence of traditional values. American Sociological Review, 19-51.

Ioannou, I., \& Serafeim, G. (2015). The impact of corporate social responsibility on investment recommendations: Analysts' perceptions and shifting institutional logics. Strategic Management Journal, 36(7), 1053-1081.

James, W. (1891). The moral philosopher and the moral life. The International Journal of Ethics, 1(3), 330-354.

Jones, T. M. (1991). Ethical decision making by individuals in organizations: An issuecontingent model. Academy of Management Review, 16(2), 366-395.

Kelley, L., Whatley, A., \& Worthley, R. (1987). Assessing the effects of culture on managerial attitudes: A three-culture test. Journal of International Business Studies, 18(2), 17-31.

Kim, C. H., Amaeshi, K., Harris, S., \& Suh, C.-J. (2013). CSR and the national institutional context: The case of South Korea. Journal of Business Research, 66(12), 2581-2591.

Kim, E. M. (1997). Big business, strong state: collusion and conflict in South Korean development, 1960-1990. Albany, NY: State University of New York Press.

Kim, J., \& Kim, J. B. (1997). Cultural differences in the crusade against international bribery: Rice-cake expenses in Korea and the foreign corrupt practices act. Pacific Rim Law \& Policy Journal, 6(3), 549-580.

Klein, S. (2002). The head, the heart, and business virtues. Journal of Business Ethics, 39(4), 347-359.

Kohlberg, L. (1976). Moral stages and moralization: The cognitive-developmental approach. In T. Lickona (Ed.), Moral development and behavior: Theory, research, and social issues (pp. 31-53). New York: Holt, Rinehart, and Winston.

Koller, J. M., \& Koller, P. J. (2007). Asian philosophies. Upper Saddle River, NJ: Pearson (Prentice Hall).

Kume, T. (1985). Managerial attitudes toward decision-making: North America and Japan. In W. B. Gudykunst, L. P. Stewart, \& S. Ting-Toomey (Eds.), Communication, culture, and organizational processes (pp. 231-251). Beverly Hills, CA: Sage publications.

Lawrence, G. (1984). A synthesis of learning style research involving the MBTI. Journal of psychological type, 8(1), 2-15.

Lee, K.-H. (1981). Ethical beliefs in marketing management: A cross-cultural study. European Journal of Marketing, 15(1), 58-67.

Lee, K.-H., \& Kim, C. H. (2014). Corporate social responsibility (CSR) practice and implementation within the institutional context: the case of the Republic of Korea. In K. C. P. Low, S. Idowu, \& S. Ang, L (Eds.), Corporate Social Responsibility in Asia (pp. 65-82). London: Springer.

Leung, K., Bhagat, R. S., Buchan, N. R., Erez, M., \& Gibson, C. B. (2005). Culture and international business: recent advances and their implications for future research. Journal of International Business Studies, 36(4), 357-378. doi:10.1057/palgrave.jibs.8400150

Levitt, T. (1983). The globalization of markets. Harvard Business Review, 61(3), 92-102. 
Lurie, Y. (2004). Humanizing business through emotions: On the role of emotions in ethics. Journal of Business Ethics, 49(1), 1-11.

McIntyre, R. P., \& Capen, M. M. (1993). A cognitive style perspective on ethical questions. Journal of Business Ethics, 12(8), 629-634.

McIntyre, R. P., Capen, M. M., \& Minton, A. P. (1995). Exploring the psychological foundations of ethical positions in marketing. Psychology \& Marketing, 12(6), 569-583.

Nisbett, R. E., Peng, K., Choi, I., \& Norenzayan, A. (2001). Culture and systems of thought: holistic versus analytic cognition. Psychological Review, 108(2), 291-310.

Paik, Y., Chow, I. H. S., \& Vance, C. M. (2011). Interaction effects of globalization and institutional forces on international HRM practice: Illuminating the convergencedivergence debate. Thunderbird International Business Review, 53(5), 647-659.

Paik, Y., \& Tung, R. L. (1999). Negotiating with East Asians: How to attain" win-win" outcomes. MIR: Management International Review, 39(2), 103-122.

Parboteeah, K. P., \& Cullen, J. B. (2003). Social institutions and work centrality: Explorations beyond national culture. Organization Science, 14(2), 137-148.

doi:10.1287/orsc.14.2.137.14989

Parker, D., \& Stacey, R. (1994). Chaos, management and economics: The implications of nonlinear thinking. London: Institute of Economic Affairs.

Pennino, C. M. (2002). Is decision style related to moral development among managers in the US? Journal of Business Ethics, 41(4), 337-347.

Preble, J. F., \& Reichel, A. (1988). Attitudes towards business ethics of future managers in the US and Israel. Journal of Business Ethics, 941-949.

Premeaux, S. R. (2004). The current link between management behavior and ethical philosophy. Journal of Business Ethics, 51(3), 269-278.

Premeaux, S. R., \& Mondy, R. W. (1993). Linking management behavior to ethical philosophy. Journal of Business Ethics, 12(5), 349-357.

Radice, H. (2000). Globalization and national capitalisms: theorizing convergence and differentiation. Review of international political economy, 7(4), 719-742.

Rawls, J. (1971). A theory of justice. Cambridge, MA: Belknap.

Redding, S. G. (1980). Cognition as an aspect of culture and its relation to management processes: An exploratory view of the Chinese case. Journal of Management Studies, 17(2), 127-148.

Rest, J. R. (1986). Moral development: Advances in research and theory. New York: Praeger.

Ricks, D. A., Toyne, B., \& Martinez, Z. (1990). Recent developments in international management research. Journal of Management, 16(2), 219-253.

Salancik, G. R., \& Pfeffer, J. (1977). An examination of need-satisfaction models of job attitudes. Administrative Science Quarterly, 22(3).

Seita, A. Y. (1997). Globalization and the Convergence of Values. Cornell International Law Journal, 30(2), 429-492.

Shenkar, O. (2001). Cultural distance revisited: Towards a more rigorous conceptualization and measurement of cultural differences. Journal of International Business Studies, 32(3), 519-535.

Siggelkow, N., \& Rivkin, J. W. (2005). Speed and search: Designing organizations for turbulence and complexity. Organization Science, 16(2), 101-122.

Snider, J., Hill, R. P., \& Martin, D. (2003). Corporate social responsibility in the 21st century: A view from the world's most successful firms. Journal of Business Ethics, 48(2), 175-187. 
Sonenshein, S. (2007). The role of construction, intuition, and justification in responding to ethical issues at work: The sensemaking-intuition model. Academy of Management Review, 32(4), 1022-1040.

Steinberg, D. I. (1989). The Republic of Korea: Economic transformation and social change. Boulder, CO: Westview Press.

Svensson, G., \& Wood, G. (2003). The dynamics of business ethics: a function of time and culture-cases and models. Management Decision, 41(4), 350-361.

Tung, R. L., Paik, Y., \& Bae, J. (2013). Korean human resource management in the global context. International Journal of Human Resource Management, 24(5), 905-921.

Vance, C. M., Groves, K. S., Paik, Y., \& Kindler, H. (2007). Understanding and measuring linear-nonlinear thinking style for enhanced management education and professional practice. Academy of Management Learning \& Education, 6(2), 167-185.

Vogel, D. (1992). The globalization of business ethics: Why America remains distinctive. California Management Review, 35(1), 30-49.

Wade, R. (1990). Governing the market: Economic theory and the role of government in East Asian industrialization. Princeton, NJ: Princeton University Press.

Webber, R. A. (1969). Convergence or divergence. Columbia Journal of World Business, 4(3), 75-83.

Whitcomb, L. L., Erdener, C. B., \& Li, C. (1998). Business ethical values in China and the US. Journal of Business Ethics, 17(8), 839-852.

White, J., \& Manolis, C. (1997). Individual differences in ethical reasoning among law students. Social Behavior and Personality, 25(1), 19-47.

You, J. (2015). Legal Perspectives on Corporate Social Responsibility: Lessons from the United States and Korea. New Delhi: Springer. 


\section{APPENDIX}

\section{Linear-Nonlinear Thinking Style Profile}

We utilized the Linear-Nonlinear Thinking Style Profile (LNTSP) developed by Vance et al. (2007) to measure the thinking style of respondents. This model defines linear thinking style as a preference for attending to external, tangible data and facts, and processing this information to make decisions. Nonlinear thinking style is defined as a preference for attending to internal feelings, impressions, and sensations, and processing this information both consciously and subconsciously to make decisions. Therefore, each of the two general thinking styles (i.e., linear vs. nonlinear) involves both attending to a particular kind of information source (internal vs. external) and subsequent mental processing of that information. The self-report LNTSP has demonstrated strong convergent validity vis-à-vis conceptually similar instruments such as the Myers-Briggs Type Indicator (MBTI) and Cognitive Style Index (Allinson and Hayes, 1996), strong external and face validity across student, professional, and managerial samples, and encouraging predictive validity in workplace contexts (Groves et al., 2008; Vance et al., 2007).

The LNTSP contains two sets of paired forced-choice items and corresponding scales of measurement. The first set of forced-choice items includes five pairs of statements that describe alternative behaviors. Using a Likert-type scale $(3=$ very often, $2=$ moderately often, $1=$ occasionally, and $0=$ rarely or never), respondents were asked to allocate exactly three points across each pair of alternative statements according to how frequently they perform such behaviors. The second set of forced-choice items included 8 paired words or phrases that influence behaviors. Using a Likert-type scale ( 3 = very strong influence on how I behave, $2=$ strong influence on how I behave, $1=$ moderate influence on how $\mathrm{I}$ behave, and $0=$ little or no influence on how I behave), respondents were asked to allocate exactly three points across each 
pair of alternative words or phrases. The LNTSP measures used in this study is presented as follows:

\begin{tabular}{ll}
\hline & \multicolumn{1}{c}{ Linear Decision-making (LDM) and Nonlinear Decision-making (NDM) } \\
\hline 1 & I primarily rely on logic when making career decisions \\
I primarily rely on my feelings when making career decisions \\
\hline I primarily weigh quantitative factors when making a decision about a large purchase \\
or investment, such as my age, budget needs, or future earnings \\
I primarily weigh qualitative factors when making a decision about a large purchase \\
or investment, such as my gut feelings or a sense that the decision is right for me \\
When my analysis and intuition are in conflict, I give precedence to my intuitive \\
insights \\
When my analysis and intuition are in conflict, I give precedence to my analytical \\
reasoning \\
The most important factor in making life-altering changes (such as a career change) \\
is feeling it is right for me \\
The most important factor in making life-altering changes (such as a career change) is \\
knowing that the change is based on objective, verifiable facts \\
When making important decisions, I pay close attention to when a number of people \\
with well-justified expertise give me the same advice \\
When making important decisions, I pay close attention when I experience a \\
"knowing in my bones," chills, tingling or other physical sensations
\end{tabular}

External Information Sources (EIS) and Inner Information Sources (IIS)

\begin{tabular}{cl}
\hline 1 & Concepts vs. Instincts \\
\hline 2 & Empathy vs. Rationality \\
\hline 3 & Reason vs. Felt Sense \\
\hline 4 & Inner Knowing vs. Logic \\
\hline 5 & Feelings vs. Facts \\
\hline 6 & Proof vs. Heartfelt \\
\hline 7 & Data vs. Hunch \\
\hline 8 & Intuition vs. Deduction \\
\hline
\end{tabular}

